Research Article

\title{
Impact of Magnesium Oxide Nanoparticles on Erythropoietin Hormone Levels in Sera of Patients with Anemia Accompanied with Diabetic Kidney Disease
}

\author{
Ameer Radhi Sultan $^{1}$, Fatin Fadhel Mohammed Al-Kazazz ${ }^{1}$, Asma Hadi Mohammed ${ }^{2}$ \\ ${ }^{1}$ Department of Chemistry, College of Science, Al-Mustansiriyah University, Iraq. \\ ${ }^{2}$ Department of Physics, College of Science, Al-Mustansiriyah University, Iraq. \\ $\square$ Corresponding authors. E-mail: ameer.radhi@yahoo.com
}

Received: Apr. 13, 2020; Accepted: Jul. 21, 2020; Published: Aug. 25, 2020

Citation: Ameer Radhi Sultan, Fatin Fadhel Mohammed Al-Kazazz, and Asma Hadi Mohammed, Impact of Magnesium Oxide Nanoparticles on Erythropoietin Hormone Levels in Sera of Patients with Anemia Accompanied with Diabetic Kidney Disease. Nano Biomed. Eng., 2020, I2(3): 232 -240. DOI: $10.5101 /$ nbe.v12i3.p232-240.

\begin{abstract}
The present research aimed to study the clinical efficacy of novel of impact of magnesium oxide nanoparticles on erythropoietin hormone in blood. Magnesium oxide nanoparticles (MgO NPs) were prepared by the chemical method. The synthesized nanoparticles were diagnosed via X-ray diffraction (XRD) and transmission electron microscopy (TEM). The average particle size was 10.8-12.6 nm. Blood samples were collected from 68 samples, classified as 24 patients with diabetic, 24 patients with diabetic kidney disease, and a control group of 20 healthy males. The age for all groups ranged between 34-72 years old. For evaluating the effectiveness of the erythropoietin (EPO) hormone with $\mathrm{MgO}$ NPs, the results showed a significant increase in the level of erythropoietin hormone with $\mathrm{MgO}$ NPs compared with the level of erythropoietin hormone without MgO NPs in patients with diabetic kidney disease (DKD). The activating percentage of erythropoietin hormone action was $84.8 \%$. In conclusion, magnesium oxide nanoparticles may exhibit an impact on erythropoietin hormone and its receptor thus improving the "action", i.e. the binding and interaction between the hormone EPO and its receptors forming their complex. Therefore, the biochemical effects and physiological effects would be more controlled and regulated, thus increasing the level of hemoglobin in the blood and reducing the anemia state.
\end{abstract}

Keywords: Binding; DKD; MgO NPs; XRD; TEM; EPO

\section{Introduction}

Chronic kidney disease (CKD) has been present for more than 3 months as an abnormality in kidney functions as a result of deteriorating kidney structure and glomerular filtration rate (GFR) [1]. Diabetic kidney disease (DKD) also previously known as diabetic nephropathy (DN) usually occurs in type 1 and type 2 diabetes mellitus (DMT1, DMT2) patients. It is defined depending on change of renal function and structure that includes the thickening of the membrane in the glomerular and tubular basement and glomerular sclerosis lead to CKD [2]. Type 2 diabetes is the most cause of DKD and chronic renal failure. In the United States, about $40 \%$ of the 29 million people with type 2 diabetes have DKD [3]. Anemia is a complication 
of chronic kidney disease and high patient mortality is associated with an increased outcome of anemia caused by kidney failure as the main cause of anemia in CKD is a deficiency of the erythropoietin hormone [4] .

Erythropoietin (EPO) is a glycoprotein hormone that consists of 165 amino acids. It $>\mathrm{s}$ synthesized via the kidneys and itss stimulated the bone marrow to produce erythrocytes [5]. Although adequate doses of the recombinant human EPO (rhuEPO) were given as a treatment, the patient still suffered from anemia [6]. Most patients with CKD have resistance to rhuEPO treatment, so they need a high dose of rhuEPO. This dose can cause harmful effects, such as high blood pressure, heart disease and thrombosis. Hence, safer and more efficient strategies for treating anemia must be found [7].

Nanotechnology is the science that enables the development of new nano materials within a nanoscale of less than $100 \mathrm{~nm}$. It is widely used in all fields because of the unique and featured physical and chemical properties of nano materials [819]. Nanoparticles (NPS) have new and important properties due to their small size and high surface area. There are numerous nanoparticles oxides which are known for their widespread use as drug delivery and treatment [20]. Magnesium oxide $(\mathrm{MgO})$ is an important essential metal oxide among various metal oxides due to versatile applications that are influenced by specific magnetic, electrical, thermal and chemical properties [21]. There has been extensive study of magnesium oxide NPs for antibacterial function, drug delivery, diagnosis and anticancer [22]. Loading the drug with nanoparticles gives the advantage like reducing side effects, targeted delivery, protecting the drug from degradation and having prolonged drug release [23]. Proteins are functionally important biomolecules, and protein binding of NPs has found critical applications in the catalysis and perception of protein structural modifications [24]. Most proteins improve the internalization of NPs into cells by interacting directly with their receptors on cell membranes [25]. The size and shape of the MgO NPs created in the research, along with other beneficial properties of MgO NPs, encouraged us to use them as an enhancer for the effectiveness of the EPO hormone.

\section{Experimental \\ Chemicals}

Magnesium nitrate $\mathrm{Mg}\left(\mathrm{NO}_{3}\right)_{2}$ and sodium hydroxide
$(\mathrm{NaOH})$ were obtained from $\mathrm{BDH}$, England and Barcelona, Spain respectively. Polyvinyl pyrrolidone $\left(\mathrm{C}_{6} \mathrm{H}_{9} \mathrm{NO}\right)_{\mathrm{n}}$ and sodium hydrogen carbonate were obtained from Sigma-Aldrich, Germany.

\section{Parameters assays}

Kits of urea, creatinin, glucose, albumin, total protein, magnesium, vitamin $\mathrm{B}_{12}$, folic acid, iron, total iron-binding capacity (TIBC), unsaturated ironbinding capacity (UIBC), ferritin, hemoglobin, and cytomegalovirus (CMV) were supplied and measured by Abbott / Architect Instrument. Erythropoietin hormone kit was supplied by Human, German Company and measured by Elisa / Epson Instrument.

\section{Preparation of MgO nanoparticles}

Co-precipitation method was used to prepare $\mathrm{MgO}$ nanoparticles. $\mathrm{Mg}\left(\mathrm{NO}_{3}\right)_{2}$ of $1 \mathrm{M}$ was dissolved with polyvinylpyrrolidone (PVP) by $50 \mathrm{~mL}$ of deionized water. Solution of $\mathrm{NaHCO}_{3}(1 \mathrm{M})$ was added to a mixture solution of $\mathrm{Mg}\left(\mathrm{NO}_{3}\right)_{2}$ and PVP under stirring at $26{ }^{\circ} \mathrm{C}$. Then, $1 \mathrm{M}$ of $\mathrm{NaOH}$ solution was slowly added to the mixture above. The white precipitate was separated and washed several times with deionized water, then dried for $1 \mathrm{~h}$ at $80{ }^{\circ} \mathrm{C}$ and calcinated at $350{ }^{\circ} \mathrm{C}$ for $3 \mathrm{~h}$. The white powder of MgO NPs was obtained [26].

\section{Subjects, samples collection and preparation samples}

About $5 \mathrm{~mL}$ of venous blood samples were taken from 68 samples classified to 24 male patients with diabetic, 24 male patients with DKD at stage 3 - 4 and 20 male healthy as control, the age for all groups ranging between 34 - 72 years old. For the purpose of studying the effect of MgO NPs in vitro on the EPO hormone, the group of patients with DKD was divided into before and after the addition of MgO NPs to the serum patients. All patients and healthy subjects were fasted for approximately $12 \mathrm{~h}$ before drawing blood.

\section{Determination of serum EPO hormone level by the ELISA kit}

Erythropoietin hormone immunoassay was used for the quantitative measurement of EPO hormone in human serum (sandwich method). This parameter was based on the immobilization of anti-erythropoietin hormone antibodies to the solid phase of the well and binding of EPO from patient serum. The bound EPO was detected with horseradish peroxidase-labeled secondary antibody that was directed with human 
EPO. Concentrations of standard (calibrator) of EPO kit were: $0,10.2,25.2,48.8,146$ and $448 \mathrm{IU} / \mathrm{L}$. The method invloved adding $200 \mu \mathrm{L}$ of DDW, $200 \mu \mathrm{L}$ of calibrator, $200 \mu \mathrm{L}$ of control positive and negative and $175 \mu \mathrm{L}$ of serum samples $+25 \mu \mathrm{L}$ of DDW into wells to determine EPO either without MgO NPs or with the presence of MgO NPs (by adding $175 \mu \mathrm{L}$ of serum samples to $25 \mu \mathrm{L}$ of MgO NPs). A $25 \mu \mathrm{L}$ of biotinylated antibody and $25 \mu \mathrm{L}$ of peroxidaselabeled secondary antibody sequentially were added to all wells. The plate was incubated in the dark at 24 ${ }^{\circ} \mathrm{C}$ for $2 \mathrm{~h}$ with shaking. After the plate was washed 5 times with $0.35 \mu \mathrm{L}$ of wash solution, $150 \mu \mathrm{L}$ of tetramethylbenzidine was added to the wells except the blank well and incubated at $24{ }^{\circ} \mathrm{C}$ for $30 \mathrm{~min}$ with shaking. $100 \mu \mathrm{L}$ of the solution was added to all wells except the blank well. After the reaction was completed, the samples were read at a wavelength of $450 \mathrm{~nm}$.

\section{Statistical test}

SPSS version 24 statistical Microsoft office was used for our research data, which included mean \pm standard deviation (SD), non-significance was defined as $p$-value $\geq 0.05$, while $p$-value $\leq 0.05$ was considered significant, with $r=$ correlation coefficient analysis that was applied to evaluate the relationship between bio tests. The results were analyzed by one-way ANOVA.

\section{Results and Discussion Characterization of Mgo NPs}

The instrument measuring X-ray diffraction patterns of pure magnesium oxide nanoparticles was Shimadzu $\mathrm{X}$-RD diffractometer, type X-RD-6000. The sample appeared in a hexagonal and cube shape according to major peaks seen at $2 \theta=36.8^{\circ}, 42.8^{\circ}, 62.1^{\circ}, 74.7^{\circ}$ and $78.4^{\circ}$ matching miller indices which include (111), (200), (220), (311) and (222) based on JCPDS PDF 0045-0946 (Fig. 1). The average size of crystallite calculated according to Scherrer formula was $10 \mathrm{~nm}$, as in Equation (1).

$D=\mathrm{k} \lambda /(\beta \cos \theta)$,

where $\mathrm{k}=0.9$ was Scherrer constant, $\lambda=0.154 \mathrm{~nm}$ referred to wavelength of the source radiations, $\beta$ was considered width at half maximum, and $\theta$ was angle of the bragg peak.

The shape of the MgO NP was also studied with transmission electron microscopy (TEM) images as

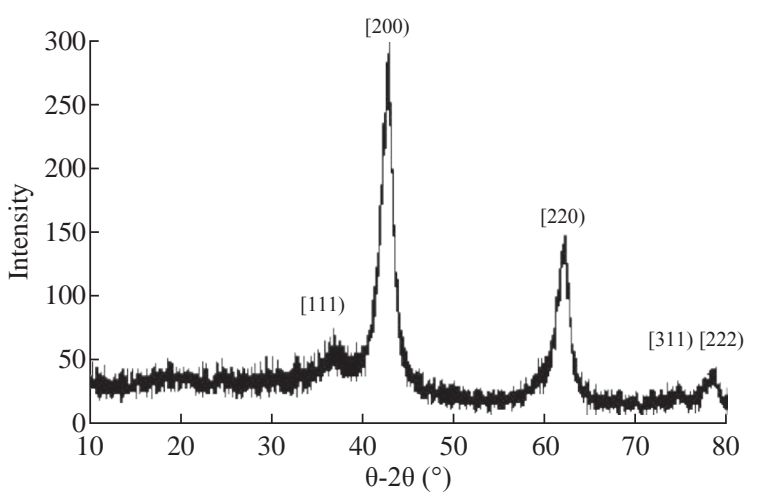

Fig. 1 X-ray diffraction of MgO NPs.

seen in Fig. 2. The morphology of the pure MgO NPs was described as spherical. The average particles size of MgO NPs were calculated randomly from the TEM figures and ranged between 10.8 and $12.6 \mathrm{~nm}$.
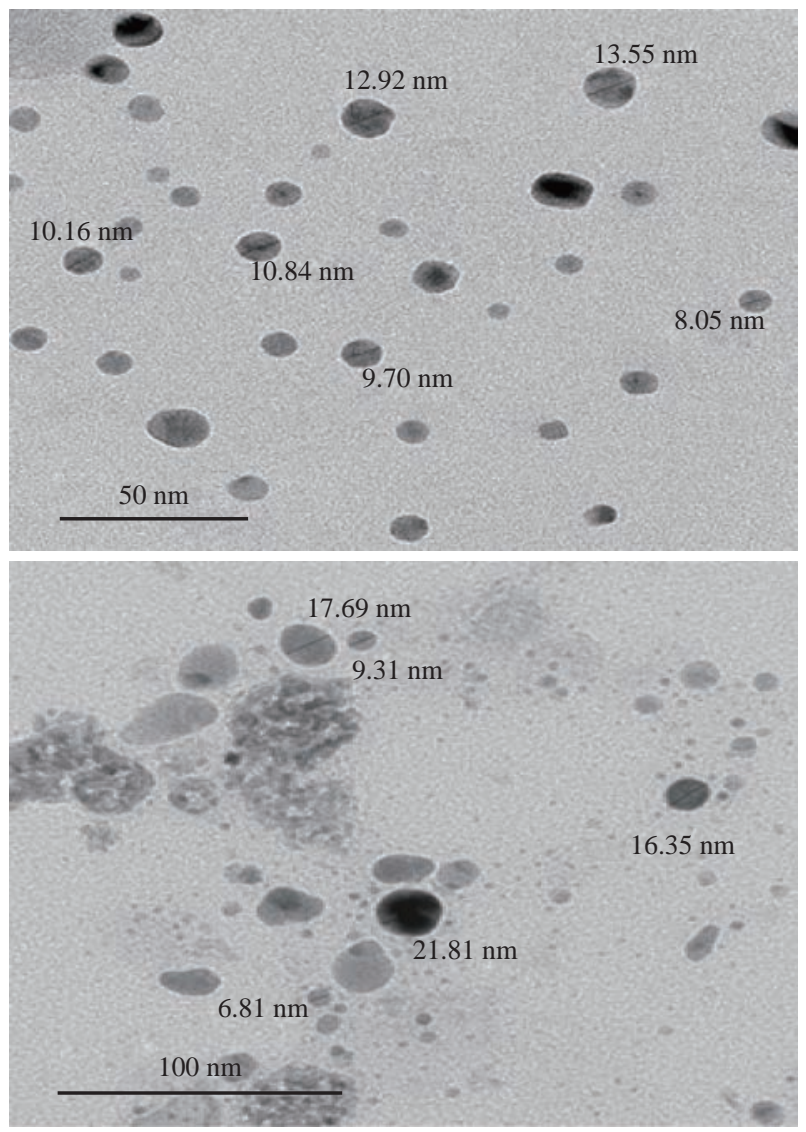

Fig. 2 Transmission electron microscopy images of MgO NPs.

\section{Diagnosis of kidney function and anemia associated with DKD}

Kidney function was evaluated by estimating the level of urea, creatinine and GFR, and by detecting anemia through estimating the levels of EPO hormone and hemoglobin, in addition to other tests affected by chronic kidney failure as listed in Table 1.

There were a highly significant increase in serum 
Table 1 Serum bio tests of patients with DMT2, DKD at stage 3 - 4 and the control group

\begin{tabular}{|c|c|c|c|c|}
\hline \multirow[b]{2}{*}{ Biotest } & \multicolumn{3}{|c|}{ Mean + SD } & \multirow[b]{2}{*}{ P-value } \\
\hline & Control, $\mathrm{n}=20$ & $\begin{array}{l}\text { Patients with diabetes mellitus } \\
\text { (DM), } \mathrm{n}=24\end{array}$ & $\begin{array}{c}\text { Patients with diabetic } \\
\text { nephropathy }(\mathrm{DN}), \mathrm{n}=24\end{array}$ & \\
\hline S. glucose (mg/dL) & $80.83 \pm 13.09^{\mathrm{a}}$ & $135.62 \pm 10.71^{\mathrm{b}}$ & $147.25 \pm 11.96^{\mathrm{c}}$ & $a \& b^{* *}, a \& c^{* *}, b \& c^{* *}$ \\
\hline S. urea (mg/dL) & $29.12 \pm 1.78^{\mathrm{a}}$ & $30.39 \pm 2.41^{b}$ & $101.74 \pm 17.39^{c}$ & $\mathrm{a} \& \mathrm{~b}, \mathrm{a} \& \mathrm{c}^{* *}, \mathrm{~b} \& \mathrm{c}^{* *}$ \\
\hline S. creatinine (mg/dL) & $0.55 \pm 0.03^{\mathrm{a}}$ & $0.58 \pm 0.03^{\mathrm{b}}$ & $3.14 \pm 0.79^{c}$ & $\mathrm{a} \& \mathrm{~b}, \mathrm{a} \& \mathrm{c}^{* *}, \mathrm{~b} \& \mathrm{c}^{* *}$ \\
\hline GFR $\left(\mathrm{mL} / \mathrm{min}\right.$ per $\left.1.73 \mathrm{~m}^{2}\right)$ & $97.47 \pm 10.59^{\mathrm{a}}$ & $89.38 \pm 20.77^{\mathrm{b}}$ & $31.85 \pm 11.38^{c}$ & $\mathrm{a} \& \mathrm{~b}, \mathrm{a} \& \mathrm{c}^{* *}, \mathrm{~b} \& \mathrm{c}^{* *}$ \\
\hline S.T. protein (g/dL) & $6.91 \pm 0.33^{\mathrm{a}}$ & $6.75 \pm 0.37^{\mathrm{b}}$ & $6.44 \pm 0.51^{\mathrm{c}}$ & $\mathrm{a} \& \mathrm{~b}, \mathrm{a} \& \mathrm{c}^{* *}, \mathrm{~b} \& \mathrm{c}^{*}$ \\
\hline S. albumine (mg/dL) & $4.23 \pm 0.26^{\mathrm{a}}$ & $4.04 \pm 0.45^{\mathrm{b}}$ & $3.69 \pm 0.6^{\mathrm{c}}$ & $\mathrm{a} \& \mathrm{~b}, \mathrm{a} \& \mathrm{c}^{* *}, \mathrm{~b} \& \mathrm{c}^{*}$ \\
\hline S. magnesium (mg/dL) & $2.34 \pm 0.12^{\mathrm{a}}$ & $2.2 \pm 0.14^{\mathrm{b}}$ & $2.11 \pm 0.19^{c}$ & $a \& b^{*}, a \& c^{* *}, b \& c$ \\
\hline S. EPO (IU/L) & $24.53 \pm 5.07^{\mathrm{a}}$ & $21.27 \pm 5.8^{\mathrm{b}}$ & $3.31 \pm 1.08^{\mathrm{c}}$ & $\mathrm{a} \& \mathrm{~b}, \mathrm{a} \& \mathrm{c}^{* *}, \mathrm{~b} \& \mathrm{c}^{* *}$ \\
\hline Hemoglobin (g/dL) & $14.27 \pm 0.97^{\mathrm{a}}$ & $13.86 \pm 0.89^{\mathrm{b}}$ & $10.52 \pm 0.78^{\mathrm{c}}$ & $\mathrm{a} \& \mathrm{~b}, \mathrm{a} \& \mathrm{c}^{* *}, \mathrm{~b} \& \mathrm{c}^{* *}$ \\
\hline $\operatorname{MCV}(\mathrm{f} / \mathrm{L})$ & $83.43 \pm 3.26^{\mathrm{a}}$ & $80.87 \pm 2.95^{\mathrm{b}}$ & $79.2 \pm 7.14^{\mathrm{c}}$ & $\mathrm{a} \& \mathrm{~b}, \mathrm{a} \& \mathrm{c}^{*}, \mathrm{~b} \& \mathrm{c}$ \\
\hline S. iron $(\mu \mathrm{g} / \mathrm{dL})$ & $113.1 \pm 23.88^{\mathrm{a}}$ & $106.87 \pm 24.53^{\mathrm{b}}$ & $86.96 \pm 22.79^{c}$ & $\mathrm{a} \& \mathrm{~b}, \mathrm{a} \& \mathrm{c}^{* *}, \mathrm{~b} \& \mathrm{c}^{*}$ \\
\hline S. TIBC $(\mu \mathrm{g} / \mathrm{dL})$ & $337.05 \pm 26.64^{\mathrm{a}}$ & $334.04 \pm 33.83^{b}$ & $308.75 \pm 41.37^{c}$ & $\mathrm{a} \& \mathrm{~b}, \mathrm{a} \& \mathrm{c}^{*}, \mathrm{~b} \& \mathrm{c}^{*}$ \\
\hline UIBC $(\mu \mathrm{g} / \mathrm{dL})$ & $224.4 \pm 11.77^{\mathrm{a}}$ & $219.57 \pm 45.1^{\mathrm{b}}$ & $221.74 \pm 33.85^{c}$ & a\&b, a\&c , b\&c \\
\hline $\mathrm{Sat} \%$ & $34.62 \pm 4.07^{\mathrm{a}}$ & $31.98 \pm 5.42^{\mathrm{b}}$ & $27.64 \pm 6.29^{c}$ & $\mathrm{a} \& \mathrm{~b}, \mathrm{a} \& \mathrm{c}^{* *}, \mathrm{~b} \& \mathrm{c}^{*}$ \\
\hline S. ferritin (ng/mL) & $57.16 \pm 9.43^{\mathrm{a}}$ & $62.01 \pm 10.26^{\mathrm{b}}$ & $52.02 \pm 8.64^{\mathrm{c}}$ & $\mathrm{a} \& \mathrm{~b}, \mathrm{a} \& \mathrm{c}, \mathrm{b} \& \mathrm{c}^{* *}$ \\
\hline S. folic acid (ng/mL) & $8.66 \pm 1.34^{\mathrm{a}}$ & $8.35 \pm 1.21^{\mathrm{b}}$ & $8.24 \pm 1.59^{c}$ & a\&b, a\&c , b\&c \\
\hline S. vitamin $B_{12}(p g / m L)$ & $654.9 \pm 80.36^{\mathrm{a}}$ & $644.58 \pm 66.91^{\mathrm{b}}$ & $598.5 \pm 56.89^{c}$ & a\&b, a\&c, b\&c \\
\hline
\end{tabular}

Note: $\mathrm{P} \geq 0.05$ (non-significant), $\mathrm{p}^{*} \leq 0.05$ (significant), $\mathrm{P}^{* *} \leq 0.01$ (highly significant).

a: The first group, i.e. control.

b: The second group, i.e. patients with DM.

c: The third group, i.e. patients with DKD.

$\mathrm{MCV}=$ mean corpuscular volume; TIBC = total iron binding capacity; UIBC $=$ unsaturated iron binding capacity calculated by S.TIBC-S.iron; Sat $\%$

$=$ iron saturation percentage calculated by $(\mathrm{S}$.iron $/ \mathrm{S}$.TIBC) $\times 100 ; \mathrm{S}=$ serum.

levels of glucose, urea, creatinine, a highly significant decrease in serum levels of total protein, albumin, magnesium, iron, sat\%, EPO, blood hemoglobin and GFR in patients with DKD compared to the control group ( $p<0.01$ ), and a significant decrease in the levels of MCV and TIBC ( $p<0.05)$. The results also showed a non-significant decrease in the levels of UIBC, ferritin, folic acid and vitamin $B_{12}$ in patients with DKD compared to the control group ( $\mathrm{p}>0.05)$.

The results also showed a highly significant increase in the serum levels of glucose, urea, creatinine, a highly significant decrease in the serum levels of EPO, ferritin, blood hemoglobin and GFR, and a significant decrease in the serum levels of total protein, albumin, iron, TIBC and sat $\%$. The results also showed nonsignificant decrease in the levels of magnesium, folic acid, vitamin $B_{12}$, UIBC and blood $\mathrm{MCV}$ in patients with DKD compared to patients with DMT2.

\section{Study of MgO NPs on EPO hormone levels of patients with DKD in vitro}

According to the results shown in Table 2, there was a highly significant decrease in the serum level of EPO hormone in DKD patients without MgO NPs and DKD patients with MgO NPs, compared to patients diabetes type $2(p<0.01)$. Also, there was a significant increase in the levels of EPO hormone in DKD patients with MgO NPs compared to EPO DKD patients without MgO NPs ( $p<0.05$ ). The activation percentages of EPO hormone was $84.8 \%$, which was calculated by comparing the EPO hormone concentration with and without $\mathrm{MgO}$ NPs, as in Equation (2) [27].

$\%$ Activation $=100 \times[$ EPO hormone with $\mathrm{MgO}$ NPs $/$ EPO hormone without MgO NPs] - 100.

Thus, $\%$ Activation $=100 \times(6.12 / 3.31)-100=$ $84.8 \%$. 
Table 2 Level of serum EPO hormone before and after the addition of MgO NPs into the serum of patients with DKD

\begin{tabular}{cll}
\hline Group & N & $\begin{array}{c}\text { Serum EPO (IU/L) } \\
\text { Mean } \pm \text { SD }\end{array}$ \\
\hline Patients diabetes type 2 & 24 & $21.27 \pm 5.8$ \\
Patients DKD without MgO NPs & 24 & $3.31 \pm 1.08$ \\
Patients diabetes type 2 & 24 & $21.27 \pm 5.8$ \\
Patients DKD With MgO NPs & 24 & $6.12 \pm 1.94$ \\
Patients DKD without MgO NPs & 24 & $3.31 \pm 1.08$ \\
Patients DKD with MgO NPs & 24 & $6.12 \pm 1.94$ \\
\hline
\end{tabular}

Note: $\mathrm{P} \leq 0.05$ considered significant; $\mathrm{p} \leq 0.01$ considered highly significant.

\section{Correlation study for EPO hormone levels in sera of patients with DKD}

Serum EPO hormone level was selected as the principal variable which was correlated with all biotests under this study. The correlation coefficient $r$ and p-value are listed in Table 3. There was a strong positive relationship between the levels of EPO without MgO NPs and with hemoglobin and GFR ( $\mathrm{r}$ $=0.56, \mathrm{r}=0.54)$ respectively, yet a moderate negative relationship for urea and creatinine $(r=-0.46, r=$ -0.45), respectively. The levels of EPO were detected without MgO NPs in sera of patients with DKD, as shown in Fig. 3.

Fig. 3 shows a moderate positive relationship was observed between EPO with MgO NPs and hemoglobin based on $r=0.41$, and there was no relationship between EPO with MgO NPs and urea, creatinine and GFR in patients with DKD.
In our current study, the effect of MgO NPs was studied on erythropoietin hormone in vitro. It was shown that there were major effects on improving and activating erythropoietin hormone action (Table 2) by about $84.8 \%$.

Panjeta et al. [28] observed that there were a highly significant increase in creatinine level and a highly significant decrease in GFR, hemoglobin and EPO hormone level in CRF patients stage 2 - 4, compared to normal controls, which is consistent with our research results.

The relationship between biotests (Table 3) and EPO in sera patients of DKD was determined with and without MgO NPs, where only a relationship appeared between EPO without MgO NPs and hemoglobin, urea, creatinine, and GFR, while only a relationship appeared between EPO with MgO NPs and hemoglobin in sera of patients with DKD. Fig. 4 shows that there

Table 3 Correlation coefficient $r$ and p-value for correlation study between biotest and EPO level (with MgO NPs and without MgO NPs)

\begin{tabular}{ccccc}
\hline \multirow{2}{*}{ Biotests } & \multicolumn{2}{c}{ EPO without MgO NPs } & \multicolumn{2}{c}{ EPO with MgO NPs } \\
\cline { 2 - 5 } \cline { 3 - 4 } Glucose & $\mathrm{r}$ & P-value & $\mathrm{r}$ & 0.101 \\
Urea & 0.060 & 0.779 & -0.067 & 0.637 \\
Creatinine & -0.46 & 0.023 & -0.11 & 0.61 \\
GFR & -0.45 & 0.026 & 0.221 & 0.3 \\
Total Protein & 0.54 & 0.006 & -0.109 & 0.613 \\
Albumine & -0.101 & 0.637 & 0.049 & 0.821 \\
Magnesium & -0.113 & 0.598 & 0.159 & 0.459 \\
Hemoglobin & 0.317 & 0.132 & 0.414 & 0.044 \\
MCV & 0.56 & 0.005 & 0.284 & 0.179 \\
S. iron & 0.114 & 0.595 & -0.372 & 0.074 \\
S. TIBC & -0.119 & 0.578 & -0.264 & 0.213 \\
UIBC & -0.060 & 0.780 & -0.040 & 0.851 \\
Sat\% & 0.007 & 0.973 & -0.150 & 0.485 \\
Ferritin & -0.142 & 0.509 & 0.019 & 0.931 \\
Folic acid & 0.074 & 0.731 & 0.013 & 0.952 \\
Vitamin $B_{12}$ & 0.066 & 0.760 & 0.109 & 0.613 \\
\hline
\end{tabular}



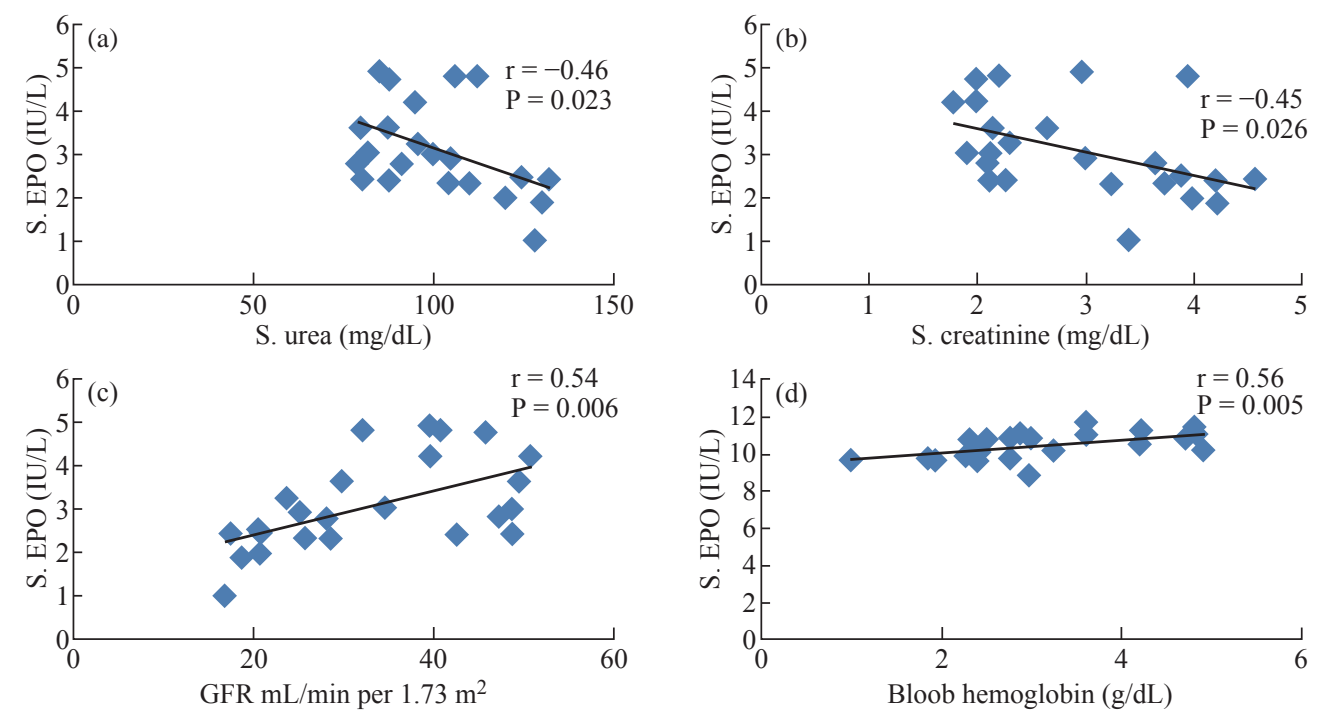

Fig. 3 Correlation between EPO without MgO NPs and (a) urea, (b) creatinine, (c) GFR, and (d) hemoglobin in patients with DKD.
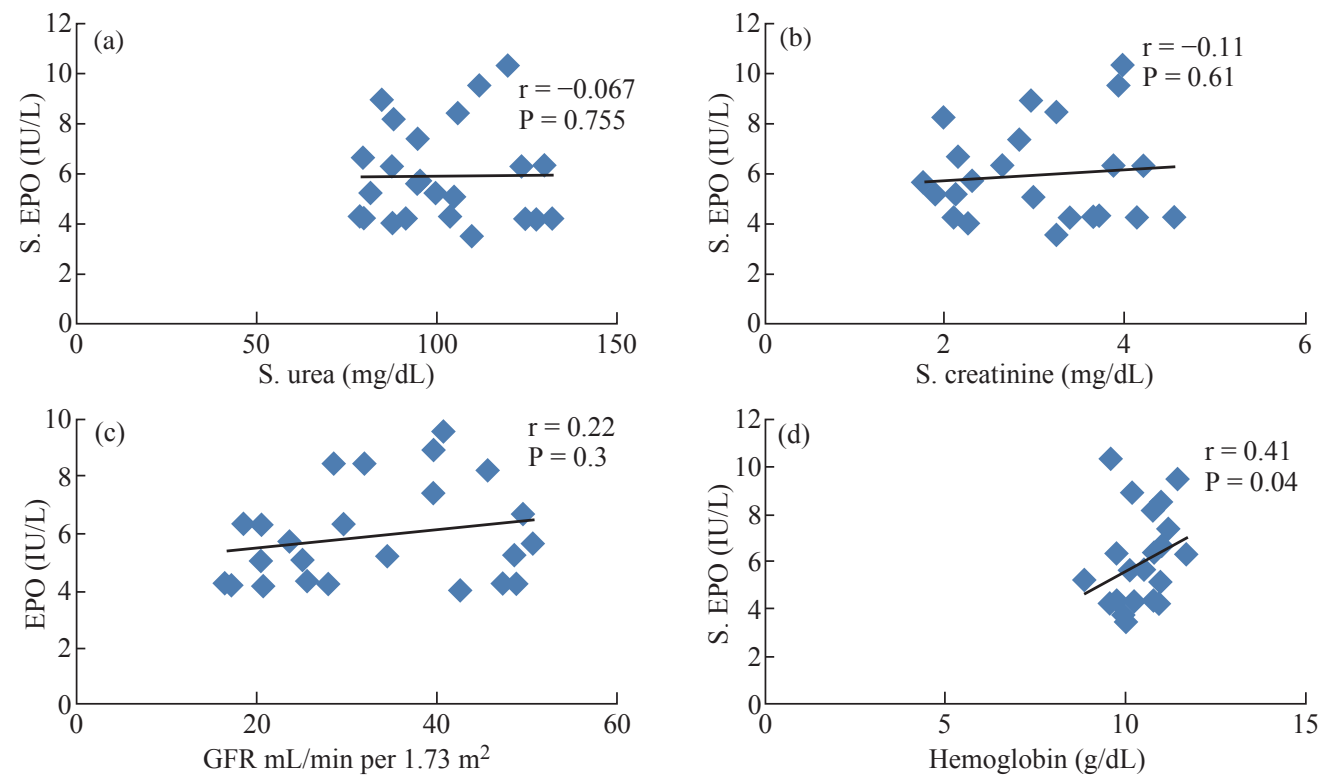

Fig. 4 Correlation between EPO with MgO NPs and (a) urea, (b) creatinine, (c) GFR, and (d) hemoglobin in patients with DKD.

was a strong positive relationship between the levels of EPO without MgO NPs and hemoglobin and GFR, while there was a moderate negative relationship between urea and creatinine. This indicates that when a kidney failure occurs, the hormone erythropoietin decreases, and thus the hemoglobin decreases and anemia occurs [29]. Anemia can occur in patients with DKD when the GFR is $<45 / 1.73 \mathrm{~m}^{2}$ due to decrease of EPO production in the kidney and the function to stimulate red blood cell from bone marrow [30]. Fig. 4 shows a moderate positive relationship between EPO with MgO NPs and hemoglobin, and there was no relationship between EPO with MgO NPs and urea, creatinine and GFR in patients with DKD. This means that the EPO increased and its function was improved with the presence of MgO NPs, so the hemoglobin level increased, and the possibility of a relationship with DKD disease disappeared. Patients with DKD often use rHuEPO drug coupled with parenteral iron therapy since iron availability is needed for effective erythropoiesis in conjunction with rHuEPO [31].

Hara et al. [32] observed that anti-EPO receptor antibodies in patients with DKD were associated with low concentrations of EPO hormone, hemoglobin, proteinuria and decrease of GFR. The researchers concluded the anti-EPOR antibodies might be involved in the progression of kidney lesions and the decline erythropoiesis in $\mathrm{T}_{2} \mathrm{D} . \mathrm{M}$ patients with $\mathrm{CKD}$ [32]. 
She et al. [33] reported that reduced EPO could be responsible for the deterioration of kidney structure and function. Their study showed that the EPO performed a direct and critical function of renal protection by binding and activating erythropoietin hormone receptor and repressing apoptosis in kidney cells [33].

The protein bonds with nanoparticles increase when the size of these particles decreases due to the increased surface area of nanoparticles. On the other hand, the size of tiny nanoparticles allows them to penetrate almost every part of the human body, including the cells [34]. Fayed et al. [35] obsorved that injection by EPO loaded with nanoparticles gave high efficacy and a longer effect period in the human body [35]. Behzadi et al. [36] demonstrated it was through hydrophobic interactions that MgO NPs formed complex with human serum albumin molecules. The study of docking based on the size of NPs showed that various linkages between MgO NPs and HSA could be formed and the CD report examined that HSA secondary structure had not been altered by MgO NPs [36].

Alfaro et al. [37] showed that magnesium was an effective drug dlivery after coating with polymer polyethylene glycol as the carrier for the 2-methoxyestradiol cancer treatment drug. Small particle size of MgO NPs as shown from TEM was an significant determinant of their biocompatibility which could be model for internalization in the intracellular [37]. Protein therapeutics such as rhuEPO injected in the skin may see internalization and biological activity restricted due to uneasy absorbance into the skin because of the very low permeability; therefore, conjugated nanoparticles with rhuEPO enhanced skin penetration properties and gave transcutaneous protein delivery efficiency [38]. Nanoparticles bind with proteins and receptor proteins of cellular. Such proteins can bind around the entire surface of the NPs [39].

Karimpour et al. [40] showed that the treatment with silver nanoparticles resulted in the increase of progesterone hormone level in the blood. Abdulsattar [41] reported that gold nanoparticles had an influence on sex hormone's binding to their receptors which led to an increase in the level of the hormone in the blood [41].

To our knowledge, the current study was the first to examine the effects of $\mathrm{MgO}$ nanoparticles on erythropoietin hormone. Therefore, the results above have confirmed that it is possible to improve the action of hormone with its receptor, and thus to improve the biochemical and physiological effects of EPO hormone and then reduce the anemia status.

\section{Conclusions}

In our current study, the effect of MgO NPs has been studied on erythropoietin hormone in vitro of patients with DKD accompanied anemia. It has been shown that there are significant effects on improving and activating erythropoietin hormone action by about $84.8 \%$. There was a positive relationship between the levels of EPO without MgO NPs and hemoglobin and GFR, while there was a moderate positive relationship between urea and creatinine. This indicates that when kidney failure occurs, the hormone erythropoietin decreases, and thus the hemoglobin decreases and anemia occurs. In addition, there was a positive relationship between EPO with MgO NPs and hemoglobin, yet there was no relationship with urea, creatinine and GFR in patients with DKD. This means that the EPO increases and its function improves with the presence of MgO NPs; hence, the hemoglobin level has increased, and the possibility of a relationship with DKD disease disappeared.

The binding of MgO NPs with EPO hormone has an impact not only on the action of EPO hormones but also on the action with its specific receptor and forming receptor-hormone $[\mathrm{RH}]$ complexe by improving the binding and interaction between the hormone EPO and its receptor. This increases the concentration and efficiency of the hormone in the blood and thus increases the level of hemoglobin in the blood.

\section{Acknowledgements}

The authors express their gratitude to M.S.C. Mohamed Ibrahim Hassan for supported in this research.

\section{Conflict of Interests}

The authors declare that no competing interest exists.

\section{References}

[1] N.M. Selby, P.J. Blankestijn, P. Boor, et al., Magnetic resonance imaging biomarkers for chronic kidney disease: A position paper from the European Cooperation in Science and Technology Action PARENCHIMA. Nephrol 
Dial Transplant, 2018, 33(2): 4-14

[2] K.Umanath, J.B. Lewis, Update on diabetic nephropathy: Core curriculum 2018. Am J Kidney Dis, 2018, 71(6): 884-895.

[3] S.M. Doshi, A.N. Friedman, Diagnosis and management of type 2 diabetic kidney disease. Clin J Am Soc Nephrol, 2017, 12: 1366-1373.

[4] D.W. Coyne, D.I.C. Goldsmith, New options for the anemia of chronic kidney disease. Kidney Int Suppl, 2017, 7(3): 157-163.

[5] D. Vocanec, T. Prijatelj, N. Debeljak, et al., Genetic variants of erythropoietin (EPO) and EPO receptor genes in familial erythrocytosis. Int J Lab Hematol, 2019, 41(2): 162-167.

[6] D. Mohan, M. Railey, Anaemia in a chronic kidney disease patient : The hidden clue. Journal of Clinical \& Experimental Nephrology, 2019, 4(2): 1-5.

[7] A.H. Ismail, H.K. Al-Bairmani, Z.S. Abbas, et al. Nanoscale synthesis of metal (II) theophylline complexes and assessment of their biological activity. Nano Biomed. Eng., 2020, 12(2): 139-147.

[8] A.M. Rheima, D.H. Hussain, and M.M. Almijbilee. Graphene-silver nanocomposite: synthesis, and adsorption study of cibacron blue dye from their aqueous solution. Journal of Southwest Jiaotong University. 2019, 54(6): 1-8.

[9] A.M. Rheima, M.A. Mohammed, S.H. Jaber, et al., Synthesis of silver nanoparticles using the UV-irradiation technique in an antibacterial application. Journal of Southwest Jiaotong University, 2019, 54(5): 1-11.

[10] A.M. Mohammed, A.M. Rheima, S.H. Jaber, et al., The removal of zinc ions from their aqueous solutions by $\mathrm{Cr}_{2} \mathrm{O}_{3}$ nanoparticles synthesized via the UV-irradiation method. Egyptian Journal of Chemistry, 2020, 1: 425431.

[11] A.M. Rheima, M.A. Mohammed, S.H. Jaber, et al., Inhibition effect of silver-calcium nanocomposite on alanine transaminase enzyme activity in human serum of Iraqi patients with chronic liver disease. Drug Invention Today, 2019, 12(11): 2818-2821.

[12] A.A. Ali, R.M. Al-Hassani, D.H. Hussain, et al., Synthesis, spectroscopic, characterization, pharmacological evaluation, and cytotoxicity assays of novel nano and micro scale of copper (II) complexes against human breast cancer cells. Drug Invention Today, 2020, 14(1): 31-39.

[13] D.H. Hussain, A.M, Rheima, and S.H. Jaber., Cadmium ions pollution treatments in aqueous solution using electrochemically synthesized gamma aluminum oxide nanoparticles with DFT study. Egyptian Journal of Chemistry, 2020, 63(2): 417-424.

[14] A.A. Ali, R.M. Al-Hassani, D.H. Hussain, et al., Fabrication of solar cells using novel micro-and nanocomplexes of triazole schiff base derivatives. Journal of Southwest Jiaotong University, 2019, 54(6): 1-19.

[15] D.H. Hussain, H.I. Abdulah, and A.M. Rheima., Synthesis and characterization of $\gamma-\mathrm{Fe}_{2} \mathrm{O}_{3}$ nanoparticles photo anode by novel method for dye sensitized solar cell. International Journal of Scientific and Research Publications, 2016, 6: 26-31.

[16] S.H. Jabber, D.H. Hussain, A.M. Rheima, et al., Comparing study of $\mathrm{CuO}$ synthesized by biological and electrochemical methods for biological activity. AlMustansiriyah Journal of Science, 2019, 30: 94-98.

[17] A.H. Ismail, H.K. Al-Bairmani, Z.S. Abbas, et al., Synthesis, characterization, spectroscopic, and biological activity studies of Nano scale $\mathrm{Zn}$ (II), Mn (II) and Fe (II) theophylline complexes. Journal of Xi'an University of Architecture \& Technology, 2020, XII (II): 2775-2789.

[18] A.H. Ismail, H.K. Al-Bairmani, Z.S. Abbas, et al.,
Nano-synthesis, spectroscopic characterisation and antibacterial activity of some metal complexes derived from Theophylline. Egyptian Journal of Chemistry, 2020, 63(7): 1-5.

[19] A.M. Rheima, D.H. Hussain, and H.I. Abdulah., Silver nanoparticles : Synthesis, Characterization and their used a counter electrodes in novel Dye sensitizer solar cell. IOSR Journal of Applied Chemistry, 2016, 9: 6-9.

[20] A.M. Rheima, M.A. Mohammed, S.H. Jaber, et al. Adsorption of selenium $\left(\mathrm{Se}^{4+}\right)$ ions pollution by pure rutile titanium dioxide nanosheets electrochemically synthesized. Desalination and Water Treatment. 2020, 194: 187-193.

[21] H.I. Abdulah, D.H. Hussain, and A.M. Rheima, Synthesis of $\alpha-\mathrm{Fe}_{2} \mathrm{O}_{3}, \gamma-\mathrm{Fe}_{2} \mathrm{O}_{3}$ and $\mathrm{Fe}_{3} \mathrm{O}_{4}$ nanoparticles by electrochemical method. Journal of Chemical, Biological and Physical Sciences, 6(4): 1288-1296

[22] T.A. Ranathunge, D. Karunaratne, R. Rajapakse, et al., Doxorubicin loaded magnesium oxide nanoflakes as ph dependent carriers for simultaneous treatment of cancer and hypomagnesemia. Nanomaterials, 2019, 9(2): 1-11.

[23] P.R. Dhapake, J.G. Avari, Application of polymeric nanoparticles in oral delivery of recombinant human erythropoietin: A review. J Drug Deliv Ther, 2019, 9: 403-407.

[24] A. Mukhopadhyay, S. Basu, S. Singha, et al., Inner-view of nanomaterial incited protein conformational changes: Insights into designable interaction. Research, 2018, 2018: 1-15.

[25] R. Cagliani, F. Gatto, and G. Bardi., Protein adsorption: A feasible method for nanoparticle functionalization? Materials, 2019, 12(12): 1-11.

[26] S. Devi Meenakshi, M. Rajarajan, S. Rajendran, et al., Synthesis and characterization of magnesium oxide nanoparticles. Elixir Nanotechnol, 2012, 50(9): 1061810620.

[27] A. Mohammed, N. Jassim, and F. Fadhel, Biochemical study for gold and silver nanoparticles on thyroid hormone levels in saliva of patients with chronic renal failure. Eur J Chem, 2013, 4(4): 353-359.

[28] M. Panjeta, I. Tahirovic, E. Sofic, et al., Interpretation of erythropoietin and haemoglobin levels in patients with various stages of chronic kidney disease. J Med Biochem, 2017, 36(2): 145-152

[29] P. Mirsad, I. Tahirovic, J. Karamehic, et al., The relation of erythropoietin towards hemoglobin and hematocrit in varying degrees of renal insufficiency. Mater Socio Medica, 2015, 27(3): 144-148.

[30] A .Mikhail, C. Brown, J.A. Williams, et al., Renal association clinical practice guideline on Anaemia of Chronic Kidney Disease. BMC Nephrol, 2017, 18(1): 1-29.

[31] S. Bajaj, B. Makkar, V. Abichandani, et al., Management of anemia in patients with diabetic kidney disease: A consensus statement. Indian J Endocrinol Metab, 2016, 20(2): 268-281.

[32] A. Hara, K. Furuichi, A. Koshino, et al., Clinical and pathological significance of autoantibodies to erythropoietin receptor in type 2 diabetic patients with CKD. Kidney Int Reports, 2018, 3(1): 133-141.

[33] J. She, Z. Yuan, Y. Wu, et al., Targeting erythropoietin protects against proteinuria in type 2 diabetic patients and in zebrafish. Mol Metab, 2018, 8(11): 189-202.

[34] J.J. Sutkovic, A review on nanoparticle and protein interaction in biomedical applications. Period Eng Nat Sci, 2016, 4(2): 34-40.

[35] B.E. Fayed, A.F. Tawfik, A. Yassin, Novel erythropoietinloaded nanoparticles with prolonged in vivo response. $J$ Microencapsul, 2012, 29(7): 650-656.

[36] E. Behzadi, R. Sarsharzadeh, M. Nouri, et al., Albumin binding and anticancer effect of magnesium oxide 
nanoparticles. Int J Nanomedicine, 2019, 14: 257-270.

[37] A. Alfaro, A. Leon, E. Guajardo-Correa, et al., MgO nanoparticles coated with polyethylene glycol as carrier for 2-Methoxyestradiol anticancer drug. PLoS One, 2019, 14(8): 1-12.

[38] A. Hyochol, W. Michael, L. Debra, et al., Nanotechnology for protein delivery: Overview and perspectives. Physiol Behav, 2017, 176(10): 139-148.

[39] W. Kreyling, S. Fertsch-Gapp, M. Schaffler, et al., In vitro and in vivo interactions of selected nanoparticles with rodent serum proteins and their consequences in biokinetics. Beilstein J Nanotechnol, 2014, 5(1): 16991711.

[40] Z. Karimpour, S. Rouzbehani, N. Naghsh, The effects of silver nanoparticles on the sex hormones and fetal development in pregnant wistar rats. J Basic Clin Med, 2016, 5(2): 7-10.

[41] A. Abdulsattar, Biological impact of gold nanoparticle on estradaiol and testosterone levels in sera of human males. J Fac Med, 2015, 57(4): 333-337.

Copyright $₫$ Ameer Radhi Sultan, Fatin Fadhel Mohammed Al-Kazazz, and Asma Hadi Mohammed. This is an open-access article distributed under the terms of the Creative Commons Attribution License, which permits unrestricted use, distribution, and reproduction in any medium, provided the original author and source are credited. 